RESEARCH REPORT

\title{
Temperament in young adulthood and later mortality: prospective observational study
}

\author{
P McCarron, D Gunnell, G L Harrison, M Okasha, G Davey Smith
}

J Epidemiol Community Health 2003;57:888-892

See end of article for authors' affiliations

...............

Correspondence to: Dr P McCarron Department of

Epidemiology and Public

Health, Queen's University Belfast, Mulhouse Building, Grosvenor Road, Belfast

BT1 2 6BJ, UK;

peter.mccarron@

qub.ac.uk

Accepted for publication 27 April 2003
Study objective: To determine the association between a clinician assessment of temperament in early adulthood and cause specific mortality.

Design: Prospective observational study.

Setting: Glasgow University.

Participants: 9239 male former students aged 16-30 (mean 20.5) years who participated in an ongoing health survey from 1948-68. A physician recorded free text assessment of temperament, which seemed to capture aspects of personality (trait) and mental health (state), was coded into: stable, anxious, schizoid, hypomanic, odd, depressed, immature, hypochondriacal, unstable, and obsessive. Associations between temperament and mortality were investigated using Cox proportional hazards models.

Main results: There were 878 deaths. Most students $-8342(90.3 \%)$-were assessed as stable, the remaining 897 (9.7\%) having at least one, and 103 (1.1\%) having more than one, temperament type. The second most common temperament was anxiety, recorded in 520 (5.6\%) students. In multivariable analyses, having at least one temperament type was associated with increased all cause and stroke mortality, hazard ratios (95\% confidence intervals): 1.23 (1.01 to 1.50 ) and 1.95 (1.06 to 3.59) respectively, compared with stable students. Students with more than one temperament type had higher risk of death from: all causes, 2.05 (1.36 to 3.09); stroke, 3.26 (1.01 to 10.56); and cancer, 2.90 (1.62 to 5.20). Anxiety was positively associated with all cause and cancer mortality, respective hazard ratios: 1.36 (1.07 to 1.72) and 1.51 (1.04 to 2.20). Men labelled hypomanic had increased cardiovascular mortality risk, 1.90 (1.05 to 3.44$)$.

Conclusions: Markers of early adult psychological distress are associated with increased mortality. Mechanisms underlying these associations require investigation.
W hile it is well known that people with psychological disorders are at increased risk of suicide, ${ }^{1}$ evidence is accumulating that symptoms of both minor and major psychological abnormality are also associated with increased mortality from other causes. ${ }^{2}$ In particular, the risk of cardiovascular disease (CVD) is greater among people with: depression, ${ }^{3-9}$ anxiety and worry, ${ }^{10-12}$ and anger and hostility. ${ }^{13-15}$ There has been less research into the association of psychological morbidity with cancer, and findings thus far are inconsistent. ${ }^{16-18}$

Most studies to date have examined the association between mental health recorded in middle age and subsequent disease risk. In these studies the possibility of reverse causality-physical disease that is already present, although perhaps clinically silent, being responsible for psychological morbidity-cannot be discounted. Few studies have investigated whether psychological conditions in early life also predict mortality from causes other than suicide. ${ }^{19}$ In a study examining the association between childhood personality and longevity after 70 years of follow up, "cheerfulness" was inversely related to longevity. ${ }^{20}$ In an early report from the Harvard and Pennsylvania Alumni follow up, several traits including anxiety, sleeplessness, feeling self conscious, or being subject to moods were more common in people who subsequently died from coronary heart disease $(\mathrm{CHD})^{21}$ or stroke. $^{22}$ More recent follow up of the same cohort has confirmed that exhaustion, as reported in an earlier univariable analysis ${ }^{23}$ is also an independent risk factor for CHD. ${ }^{24}$ In the Johns Hopkins Precursors study, medical students, who in 1948-68 reacted to stressful situations with anxiety, and loss of appetite and sleep, were at higher risk of mortality compared with those who reacted with anger or were stable. ${ }^{25}$
In another college based study, students with higher hostility scores were more likely after 21-23 years follow up to consume more caffeine, to have a greater body mass index (BMI) and a higher cholesterol:HDL cholesterol ratio and to be current smokers compared with those with lower hostility scores. ${ }^{26}$ Finally, in a population based cohort study, high hostility level predisposed young adults to coronary artery calcification-a marker of atherosclerosis and coronary risk factors in older adults ${ }^{27}$-after 10 years follow up. ${ }^{28}$

Investigation of the relation between measures of personality or psychological morbidity in early adulthood and later cause specific mortality may improve understanding of the aetiology of chronic diseases and thus help inform future preventative initiatives. Such studies are important, particularly in the light of recent findings that indicate that the prevalence of mental disorder is high; in the National Psychiatric Morbidity Survey in Great Britain, 16.6\% of 2024 year olds were identified as having a psychiatric disorder. ${ }^{29}$ We report on the association between a crude assessment of young adult personality and mental health and cause specific mortality in a large cohort of male students attending Glasgow University between 1948 and 1968.

\section{METHODS}

\section{Design}

Full details of the Glasgow Student Cohort Study are presented elsewhere. ${ }^{30}$ Briefly, students attending Glasgow

Abbreviations: $C H D$, coronary heart disease; CVD, cardiovascular disease; $\mathrm{BMI}$, body mass index 


\section{Key points}

- Current evidence suggests that symptoms of psychological distress are associated with increased risk of cardiovascular disease but most studies have been carried out in middle age.

- The prognostic implications of routine measures of young adult temperament on later health have not been investigated.

- Aspects of temperament and mental health in early adulthood, as indexed by a crude clinical assessment at a routine medical examination are associated with higher risk of all cause, stroke and cancer mortality in later life.

- Although replication of these findings in studies with more robust measures of psychological morbidity is required, the results do suggest that aspects of psychological health and temperament in early adulthood may be important determinants of future physical wellbeing.

University between 1948 and 1968 were invited to participate in a medical examination carried out in the Student Health Department. A questionnaire was administered and a clinical examination was carried out. Data collected included sociodemographic information, details of health behaviours, and medical history, and, in addition, measurements of blood pressure, height, and weight.

\section{Measurement of exposures}

A box in the health questionnaire labelled "personality" prompted a free text assessment by the examining physician. The assessments recorded in this box indicate that the physicians were assessing a mixture of concurrent psychiatric symptomatology, with free text comments such as "depressed", "anxious" and, "hypomanic", as well as aspects of students' personality at the time of examination, with comments such as "immature" and "schizoid". As the examining doctors were not recording the more precise construct of personality in itself and as we recognise the limitations of the measure in this regard, we have chosen to refer to the original physician assessment as temperament throughout the remainder of the paper. Before the analyses, a psychiatrist (GH) and an epidemiologist with an interest in psychiatric disorders (DG) coded the temperament assessments into 11 broad categories. Students who did not have an atypical temperament assessment were categorised as "stable" - the term used by the examining physicians. Because it appears that these doctors were attempting to detect atypical temperaments we have chosen to include in the "stable" category students who were variously described as "cheerful", "pleasant", "quiet", "sensible", and "well balanced". Further justification for this is that where these terms occurred in the original assessments it was almost always in combination with the term "stable". Where the category term or a variation of that term (for example, depressive, depressed) appeared, the person was assigned to that category. Other summary descriptive statements (variations given in parentheses) were assigned to specific categories as follows: (i) anxious, (worried, sleeplessness); (ii) schizoid, (introverted, reticent, inhibited, unemotional); (iii) hypomanic, (volatile); (iv) odd, (abnormal); (v) depressed, (breakdown, mental breakdown, up and down); (vi) immature; (vii) hypochondriacal, (preoccupied-with health related matters); (viii) unstable (emotional, emotional instability); (ix) obsessive; (x) paranoid and; (xi) inadequate.
Two further categories were created: one for people who had at least one atypical temperament recorded, regardless of its categorisation, and another for people who had more than one category of atypical temperament recorded.

\section{Measurement of outcome}

The National Health Service Central Register (NHSCR) in Edinburgh and its English equivalent in Southport carried out tracing of the students who took part in the original examinations. Dates of birth together with surname and forename were used to trace the cohort. For people who have been successfully identified using the NHSCR we are notified of date and cause of death, area of current residence, and emigration details.

\section{Statistical analyses}

Analyses are limited to men as there have been comparatively few female deaths. Men aged over 30 years at the time of examination, or who had emigrated from the UK at an undetermined date were also excluded from the analyses. Deaths were coded using the ninth revision of the International Classification of Diseases (ICD 9). Mortality rates for each cause of death per 1000 men in each temperament category were calculated. Cox proportional hazards models were then used to examine associations between temperament and mortality from the following causes: all cause; CVD (ICD 9: 390-459); CHD (ICD 9: 410414); stroke (ICD 9: 430-438); cancer (ICD 9: 140-208); and mortality from accidents, suicides, and violence (ICD 9: 800999). As there were fewer than 10 deaths among those classified as depressed, immature, hypochondriacal, or unstable we did not examine cause specific mortality patterns for these category types. Age adjusted and multivariable hazard ratios were computed. The following potential confounding factors were included in the multivariable models: smoking (none, 1-10, 11-20 and >20 cigarettes per day) father's social class $(\mathrm{I}-\mathrm{V})$, height $(\mathrm{m})$ and BMI $\left(\mathrm{kg} / \mathrm{m}^{2}\right)$, and both maternal and paternal vital status (alive, dead). For all cause, CVD, CHD, and stroke mortality additional adjustment was made for systolic blood pressure $(\mathrm{mm} \mathrm{Hg})$. All analyses were performed using Stata version 7.0 (StataCorp, College Station, TX, USA).

\section{RESULTS}

A total of 11755 male students, of whom 11043 were aged 16-30 years at the time of examination and had data on temperament, participated in the original survey. Of these, $9239(83.7 \%)$, have been traced, and are representative of the original participants in terms of social class, height, weight,

Table 1 Proportion of male students in each temperament category*

\begin{tabular}{ll}
\hline Temperament type & Number (\%) \\
\hline None (stable) & $8342(90.3)$ \\
At least one & $897(9.7)$ \\
More than one & $103(1.1)$ \\
Anxious & $520(5.6)$ \\
Schizoid & $238(2.6)$ \\
Hypomanic & $120(1.3)$ \\
Odd & $5(0.1)$ \\
Depressed & $14(0.2)$ \\
Immature & $55(0.6)$ \\
Hypochondriacal & $19(0.2)$ \\
Unstable & $30(0.3)$ \\
Obsessive & $1(0.0)$ \\
Paranoid & $0(0)$ \\
Inadequate & $0(0)$
\end{tabular}

*The same person may appear in more than one row if more than one temperament trait was identified. 
Table 2 Baseline characteristics* of male students according to temperament type

\begin{tabular}{|c|c|c|c|c|c|c|c|}
\hline Temperament type & Age (y) & $\mathrm{SBP}(\mathrm{mm} \mathrm{Hg})$ & Height $(m)$ & BMI (kg/m2) & $\begin{array}{l}\text { Social class } \\
\text { I and || (\%) }\end{array}$ & $\begin{array}{l}\text { Non-smoker } \\
(\%)\end{array}$ & $\begin{array}{l}\text { Non-drinker } \\
(\%)\end{array}$ \\
\hline Stable & $20.5(2.7)$ & $130.2(12.8)$ & $174.8(6.4)$ & $21.6(2.2)$ & 56.0 & 66.8 & 45.0 \\
\hline At least one & $21.0(2.9)$ & $135.4(14.8)$ & $174.5(6.4)$ & $21.0(2.1)$ & 54.8 & 67.4 & 53.9 \\
\hline More than one & $21.3(2.7)$ & 136.1 (16.2) & $174.5(5.6)$ & $20.8(2.3)$ & 59.0 & 67.3 & 49.4 \\
\hline Anxious & $21.3(3.0)$ & $135.6(14.8)$ & $174.3(6.4)$ & $20.9(2.1)$ & 53.2 & 66.6 & 49.8 \\
\hline Schizoid & $21.0(2.7)$ & $133.4(13.9)$ & $174.8(6.2)$ & $21.3(2.2)$ & 57.4 & 67.6 & 51.6 \\
\hline Hypomanic & $20.9(2.8)$ & $143.0(16.4)$ & $175.3(6.1)$ & $20.8(2.0)$ & 62.7 & 69.2 & 72.4 \\
\hline Odd & $19.4(2.6)$ & $126.4(7.9)$ & $167.6(4.8)$ & $20.7(2.0)$ & 40.0 & 75.0 & 50.0 \\
\hline Depressed & $20.6(1.6)$ & $124.8(12.2)$ & $175.1(7.6)$ & $21.1(1.8)$ & 58.3 & 35.7 & 45.5 \\
\hline Immature & $18.9(1.6)$ & $132.7(13.4)$ & $172.5(6.1)$ & $20.0(2.0)$ & 53.7 & 77.4 & 71.2 \\
\hline Hypochondriacal & $22.9(3.4)$ & $131.0(12.5)$ & $173.6(6.0)$ & $21.5(2.2)$ & 55.6 & 57.9 & 14.3 \\
\hline Unstable & $21.4(3.4)$ & $133.6(14.5)$ & $175.3(6.2)$ & $20.6(2.5)$ & 50.0 & 71.4 & 38.0 \\
\hline
\end{tabular}

and blood pressure. ${ }^{30}$ Mean age at examination was 20.5 (range 16-30) years. Among traced participants none were labelled paranoid or inadequate and only one was labelled obsessive. These categories were therefore not included in the single category analyses but the person categorised as obsessive was retained in the analyses for at least one, and greater than one temperament type. Traced participants were slightly less likely to be positive for at least one temperament type compared with non-traced participants $9.8 \%$ versus $11.5 \%, \mathrm{p}=0.024$.

Table 1 shows the distribution of temperament type. Most (90.3\%) students were coded stable, 897 (9.7\%) students had at least one atypical temperament type, and 103 (1.1\%), more than one. The most common specific atypical temperament type was anxiety with $520(5.6 \%)$ men in this category.

The characteristics of the students at the time of examination in relation to temperament category are shown in table 2 . Compared with students labelled stable, students with at least one recorded atypical temperament type were slightly older, had lower BMI but had higher systolic blood pressure. They were also more likely to smoke and they consumed less alcohol, and they were more likely to come from lower socioeconomic backgrounds.

Over the median follow up time of 40.9 years there were 878 deaths among traced study members. Table 3 shows mortality rates per 1000 men per year for all causes and specific causes. For each temperament category overall mortality was higher for those participants who had an atypical temperament compared with those who were stable. Those students who were labelled depressed had the highest all cause mortality, followed by students who were positive for more than one temperament type.
Univariable and multivariable analyses examining the association between each temperament type and all cause and cause specific mortality are presented in table 4 . As there was little difference in the results from univariable analyses carried out on the full cohort and results from analyses that included only those participants with complete data on possible confounders-8385 $(90.7 \%)$ traced eligible participants - the latter are reported here. Compared with students who were stable, students with at least one atypical temperament type were at increased risk of all cause mortality and were almost twice as likely to die from stroke. The mortality risks for these causes of death and for cancer were even larger for students who had more than one atypical temperament type. Students who were anxious were at moderately increased risk of all cause and cancer mortality compared with stable students. Men classified as depressed, had high all cause mortality. Men who were categorised as hypomanic were almost twice as likely to die from CVD as stable students. There was little evidence that students who were categorised as schizoid or hypomanic were at increased mortality risk. Controlling for confounders had little effect on the univariable associations. Data on alcohol consumption were available on 7400 men, but additional inclusion of this variable in the regression models made little difference to the above findings (data not shown).

\section{DISCUSSION}

Our findings show that a brief clinician assessment of a crude measure of temperament and mental health in early adulthood can predict later mortality risk. This observation points to the importance of psychological adjustment in early adulthood in predicting future mortality risk and extends

Table 3 Mortality rate per 1000 men for each cause of death by temperament type*

\begin{tabular}{|c|c|c|c|c|c|c|c|c|c|c|c|c|}
\hline \multirow[b]{2}{*}{ Temperament type } & \multicolumn{2}{|c|}{ All causes } & \multicolumn{2}{|c|}{ Cardiovascular disease } & \multicolumn{2}{|c|}{$\begin{array}{l}\text { Coronary } \\
\text { heart disease }\end{array}$} & \multicolumn{2}{|c|}{ Stroke } & \multicolumn{2}{|c|}{ Cancer } & \multicolumn{2}{|c|}{$\begin{array}{l}\text { Accidents suicide } \\
\text { and violence }\end{array}$} \\
\hline & rate & $\mathbf{n}$ & rate & $\mathbf{n}$ & rate & $\mathbf{n}$ & rate & $\mathbf{n}$ & rate & $\mathbf{n}$ & rate & $\mathbf{n}$ \\
\hline Stable & 2.20 & 745 & 0.86 & 292 & 0.64 & 218 & 0.16 & 54 & 0.79 & 267 & 0.18 & 61 \\
\hline At least one & 3.43 & 133 & 1.47 & 57 & 0.83 & 32 & 0.39 & 15 & 1.24 & 48 & 0.26 & 10 \\
\hline More than one & 5.62 & 24 & 1.80 & 8 & 0.67 & 3 & 0.67 & 3 & 2.92 & 13 & 0.22 & 1 \\
\hline Anxious & 3.80 & 85 & 1.39 & 31 & 0.67 & 15 & 0.36 & 8 & 1.57 & 35 & 0.31 & 7 \\
\hline Schizoid & 3.02 & 31 & 1.17 & 12 & 0.68 & 7 & 0.39 & 4 & 1.17 & 12 & 0.19 & 2 \\
\hline Hypomanic & 3.87 & 21 & 2.21 & 12 & 1.29 & 7 & 0.55 & 3 & 1.48 & 8 & 0 & 0 \\
\hline Depressed & 7.64 & 4 & - & - & - & - & - & - & - & - & - & - \\
\hline Immature & 2.52 & 6 & - & - & - & - & - & - & - & - & - & - \\
\hline Hypochondriacal & 4.81 & 4 & - & - & - & - & - & - & - & - & - & - \\
\hline Unstable & 4.59 & 6 & - & - & - & - & - & - & - & - & - & - \\
\hline
\end{tabular}

*Total number deaths $=745+133$. Single temperament categories may include deaths that occur in more than one category. Number duplicated deaths $=24-$ accounted for in the "more than one" category. 


\begin{tabular}{|c|c|c|c|c|c|c|}
\hline $\begin{array}{l}\text { Temperament } \\
\text { type }\end{array}$ & All cause & $\begin{array}{l}\text { Cardiovascular } \\
\text { disease }\end{array}$ & $\begin{array}{l}\text { Coronary } \\
\text { heart disease }\end{array}$ & Stroke & All cancer & $\begin{array}{l}\text { Accidents, suicide } \\
\text { and violence }\end{array}$ \\
\hline Stable & $\begin{array}{l}1.00 \\
1.00\end{array}$ & $\begin{array}{l}1.00 \\
1.00\end{array}$ & $\begin{array}{l}1.00 \\
1.00\end{array}$ & $\begin{array}{l}1.00 \\
1.00\end{array}$ & $\begin{array}{l}1.00 \\
1.00\end{array}$ & $\begin{array}{l}1.00 \\
1.00\end{array}$ \\
\hline \multicolumn{7}{|l|}{ At least one } \\
\hline $\begin{array}{l}\text { Age adjusted } \\
\text { Fully adjusted }\end{array}$ & $\begin{array}{l}1.22(1.00 \text { to } 1.48)^{*} \\
1.23(1.01 \text { to } 1.50)^{*}\end{array}$ & $\begin{array}{l}1.32(0.98 \text { to } 1.78) \\
1.28(0.94 \text { to } 1.74)\end{array}$ & $\begin{array}{l}0.94(0.63 \text { to } 1.42) \\
0.90(0.59 \text { to } 1.35)\end{array}$ & $\begin{array}{l}1.83(1.01 \text { to } 3.31)^{*} \\
1.95(1.06 \text { to } 3.59)^{*}\end{array}$ & $\begin{array}{l}1.16(0.83 \text { to } 1.61) \\
1.20(0.87 \text { to } 1.68)\end{array}$ & $\begin{array}{l}1.40(0.69 \text { to } 2.85) \\
1.47(0.72 \text { to } 3.03)\end{array}$ \\
\hline \multicolumn{7}{|c|}{ More than one } \\
\hline $\begin{array}{l}\text { Age adjusted } \\
\text { Fully adjusted }\end{array}$ & $\begin{array}{l}2.04(1.36 \text { to } 3.06)^{* *} \\
2.05(1.36 \text { to } 3.09)^{* *}\end{array}$ & $\begin{array}{l}1.67(0.83 \text { to } 3.36) \\
1.60(0.79 \text { to } 3.25)\end{array}$ & $\begin{array}{l}0.88(0.28 \text { to } 2.74) \\
0.83(0.26 \text { to } 2.60)\end{array}$ & $\begin{array}{l}3.07(0.96 \text { to } 9.81) \\
3.26(1.01 \text { to } 10.56)^{*}\end{array}$ & $\begin{array}{l}2.79(1.56 \text { to } 4.98)^{* *} \\
2.90(1.62 \text { to } 5.20) \text { ** }\end{array}$ & $\begin{array}{l}{ }^{*} 1.27(0.17 \text { to } 9.16) \\
{ }^{*} 1.26(0.17 \text { to } 9.14)\end{array}$ \\
\hline \multicolumn{7}{|c|}{ (1) } \\
\hline $\begin{array}{l}\text { Age adjusted } \\
\text { Fully adjusted }\end{array}$ & $\begin{array}{l}1.37(1.08 \text { to } 1.73)^{*} \\
1.36(1.07 \text { to } 1.72)^{*}\end{array}$ & $\begin{array}{l}1.24(0.85 \text { to } 1.82) \\
1.18(0.80 \text { to } 1.73)\end{array}$ & $\begin{array}{l}0.83(0.48 \text { to } 1.43) \\
0.77(0.45 \text { to } 1.33)\end{array}$ & $\begin{array}{l}1.42(0.64 \text { to } 3.11) \\
1.43(0.65 \text { to } 3.19)\end{array}$ & $\begin{array}{l}1.48(1.02 \text { to } 2.15)^{*} \\
1.51(1.04 \text { to } 2.20)^{*}\end{array}$ & $\begin{array}{l}1.89(0.86 \text { to } 4.16) \\
1.93(0.88 \text { to } 4.27)\end{array}$ \\
\hline \multicolumn{7}{|c|}{ Schizoid } \\
\hline Age adjusted & 1.00 (0.67 to 1.48$)$ & $0.96(0.51$ to 1.80$)$ & $0.67(0.28$ to 1.64$)$ & $1.89(0.69$ to 5.21$)$ & 0.94 (0.48 to 1.82$)$ & $1.15(0.28$ to 4.70$)$ \\
\hline Fully adjusted & 1.00 (0.67 to 1.48$)$ & 0.93 (0.49 to 1.74$)$ & $0.64(0.26$ to 1.56$)$ & $1.98(0.71$ to 5.46$)$ & 0.95 (0.49 to 1.85$)$ & $1.14(0.28$ to 4.67$)$ \\
\hline \multicolumn{7}{|c|}{ Hypomanic } \\
\hline Age adjusted & 1.39 (0.90 to 2.15$)$ & $2.00(1.12 \text { to } 3.55)^{*}$ & 1.63 (0.77 to 3.35$)$ & $2.82(0.85$ to 9.31$)$ & $1.44(0.71$ to 2.90$)$ & - \\
\hline Fully adjusted & $1.41(0.91$ to 2.20$)$ & $1.90(1.05 \text { to } 3.44)^{*}$ & 1.49 (0.69 to 3.23 ) & $2.66(0.81$ to 8.74$)$ & 1.50 (0.74 to 3.03$)$ & - \\
\hline \multicolumn{7}{|c|}{ Depressed } \\
\hline Age adjusted & $4.11(1.54 \text { to } 11.00)^{* *}$ & $=$ & - & - & - & - \\
\hline Fully adjusted & $4.26(1.59 \text { to } 11.40)^{* *}$ & - & - & - & - & - \\
\hline \multicolumn{7}{|l|}{ Immature } \\
\hline Age adjusted & 1.28 (0.57 to 2.86$)$ & - & - & - & - & - \\
\hline Fully adjusted & 1.47 (0.66 to 3.30$)$ & - & - & - & - & - \\
\hline \multicolumn{7}{|c|}{ Hypochondriacal } \\
\hline Age adjusted & $1.39(0.52$ to 3.71$)$ & - & - & - & - & - \\
\hline Fully adjusted & $1.29(0.48$ to 3.46$)$ & - & - & - & - & - \\
\hline \multicolumn{7}{|l|}{ Unstable } \\
\hline Age adjusted & $0.93(0.30$ to 2.89$)$ & - & - & - & - & - \\
\hline Fully adjusted & 1.07 (0.34 to 3.34 ) & - & - & - & - & - \\
\hline
\end{tabular}

†Fully adjusted analyses: adjusted for smoking, father's social class, BMI, maternal and paternal vital status. In models examining all cause, cardiovascular, coronary heart disease, and stroke mortality systolic blood pressure was also controlled for. ${ }^{*} p<0.05,{ }^{* *} p<0.01$.

previous findings reporting associations between mental health and mortality.

This is a large prospective study in which temperament was measured many years before death occurred, ruling out the problem of reverse causality. Data on several potential confounding variables, including parental vital status, were available but controlling for these had little influence on the overall effect estimates. Apart from anxiety, few students had any other atypical temperament codings, thus decreasing the power of the analyses, as reflected in the occasionally wide confidence intervals. Also, as students attending university during the period of the study were overwhelmingly from affluent backgrounds ${ }^{30}$ and participants in the health survey comprised $50 \%$ of the male student population of Glasgow University, there could be selection bias. It is also possible that the associations with temperament may be different among people from poorer backgrounds than those represented in this study, because of associations between socioeconomic position and the occurrence of stressful life events, low social support, and other psychosocial factors that have been linked to in particular, CVD risk, ${ }^{31}$ and also because of the association with potential differential access to health services.

\section{Measurement and meaning of temperament}

The major limitation of the study is that the assessment of temperament was not standardised. Essentially, the assessments were impressionistic free text codings of a global assessment that seemed to capture elements of state (mental health at the time of the assessment) and trait (personality). Our stratification of these free text statements into broad categories of temperament is likely to represent a conflation of trait and state psychological markers, with uncontrolled variability in thresholds for recognition and severity. Nevertheless, the prevalence of atypical temperament types reported here is broadly comparable with rates of psychological distress reported in other unselected population studies, ${ }^{29}$ lending some credence to their usefulness as markers for different domains of mental health.

\section{Explanations of findings}

Several mechanisms may account for the current findings. An important consideration is whether the findings may be explained by residual confounding. Although controlling for several important confounding variables had little effect on the results, one of these variables, father's social class, is a comparatively crude indicator of the socially patterned exposures in childhood. However, while we have no information on the students' socioeconomic circumstances after graduation, it is probable that the majority (over $75 \%$ ) had affluent social positions in later adulthood. ${ }^{32}$ Temperament in young adulthood could, of course, influence later mortality risk through its influences on later life social circumstances.

The role of health behaviours, such as smoking and alcohol consumption, may be important in explaining the findings. Men who were positive for at least one atypical temperament assessment were more likely to smoke than stable people. Controlling for tobacco and alcohol intake had little effect on the findings, but as with social class, these measures, crudely assessed at one point in time, may give a poor indication of participants' subsequent adherence to these health behaviours. It is known, for example, that depressed people are less likely to quit smoking ${ }^{33}$ and therefore may be at increased risk of CVD and certain cancers in later life, compared with non-depressed people. The strong association between depression and all cause mortality although based on small numbers of deaths (two from CVD and two from cancer), provides some support for this hypothesis.

A range of biological mechanisms for the positive associations between psychiatric morbidity and CVD have been advanced. These include the greater prevalence of adverse 
health behaviours in those with psychiatric illness and disordered autonomic function leading to changes in heart rate variability and subsequent hypertension. ${ }^{34}$ In keeping with this latter explanation, systolic blood pressure was somewhat higher in those with one or more atypical temperament types. While controlling for systolic blood pressure did not affect the findings, the fact that blood pressure tracks into late adulthood ${ }^{35}$ points to the likelihood that people with raised blood pressure in early adulthood are also at increased risk of hypertension and therefore CVD in later life. Other potential mechanisms that have been proposed to explain associations between psychological morbidity and later mortality include deleterious changes in lipid metabolism, ${ }^{36}{ }^{37}$ promotion of cardiovascular risk through increased basal levels of cortisol in adulthood ${ }^{38} 39$ as a result of early life stressors, ${ }^{40}$ and increased platelet activity secondary to depression leading to accelerated the thrombin formation and atherosclerosis. ${ }^{41}$ Evidence on these pathways is currently thin, however.

\section{Conclusions}

Psychological wellbeing has been recognised as an important factor for students in determining both educational and later occupational performance. We have shown that health in later life may also be dependent on personality/psychological health-although measured in a comparatively crude wayin early adulthood. The findings are provocative but the limitations highlighted point to the need for replication of the analyses in studies with standardised early life measures of mental health and with detailed measures of later life mediating factors.

\section{ACKNOWLEDGEMENTS}

The authors would like to thank Alan Kerr, Christine Hamilton, and Heather Learmonth for help with data entry.

\section{CONTRIBUTORS}

PMCC and GDS discovered the data and set up the study. PMcC, DG and GLH originated the hypothesis and contributed to the design and conduct of the study. DG and GLH devised the coding scheme for the original assessments. PMcC carried out the analyses and drafted the paper and received critical contributions from the other co-authors. PMcC will act as guarantor.

\section{Authors' affiliations}

P McCarron, N Ireland Cancer Registry, Department of Epidemiology and Public Health, The Queen's University of Belfast, UK

D Gunnell, M Okasha, G Davey Smith, Department of Social Medicine, University of Bristol, Bristol, UK

G Harrison, Division of Psychiatry, University of Bristol

Funding: Chest Heart and Stroke (Scotland), Stroke Association, NHS Management Executive, Cardiovascular Disease and Stroke Research and Development Initiative.

Conflicts of interest: none declared.

\section{REFERENCES}

1 Harris EC, Barraclough B. Suicide as an outcome for mental disorders: a metaanalysis. Br J Psychiatry 1997; 170:205-28.

2 Huppert FA, Whittington JE. Symptoms of psychological distress predict 7-year mortality. Psychol Med 1995;25:1073-86.

3 Anda R, Williamson D, Jones D, et al. Depressed affect, hopelessness, and the risk of ischemic heart disease in a cohort of US adults. Epidemiology 1993;4:285-94.

4 Aromaa A, Raitasalo R, Reunanen A, et al. Depression and cardiovascular diseases. Acta Psychiatr Scand Suppl 1994;377:77-82.

5 Murphy JM, Laird NM, Monson RR, et al. A 40-year perspective on the prevalence of depression: the Stirling County Study. Arch Gen Psychiatry 2000;57:209-15.

6 Barefoot JC, Schroll M. Symptoms of depression, acute myocardial infarction, and total mortality in a community sample. Circulation 1996;93:1976-80.
7 Ford DE, Mead LA, Chang PP, et al. Depression is a risk factor for coronary artery disease in men. Arch Intern Med 1998;158:1422-6.

8 Sesso HD, Kawachi I, Vokonas PS, et al. Depression and the risk of coronary heart disease in the Normative Aging Study. Am J Cardiol 1998;82:851-6.

9 Penninx BW, Beekman AT, Honig A, et al. Depression and cardiac mortality: results from a community-based longitudinal study. Arch Gen Psychiatry $2001 ; 58: 221-7$.

10 Kawachi I, Colditz GA, Ascherio A, et al. Prospective study of phobic anxiety and risk of coronary heart disease in men. Circulation 1994:89:1992-7.

11 Kubzansky LD, Kawachi I, Spiro A 3rd, et al. Is worrying bad for your heart? A prospective study of worry and coronary heart disease in the Normative Aging Study. Circulation 1997;95:818-24.

12 Weissman MM, Markowitz JS, Ouellette R, et al. Panic disorder and cardiovascular/cerebrovascular problems: results from a community survey. Am J Psychiatry 1990;147:1504-8.

13 Gallacher JE, Yarnell JW, Sweetnam PM, et al. Anger and incident heart disease in the caerphilly study. Psychosom Med 1999;61:446-53.

14 Williams JE, Paton CC, Siegler IC, et al. Anger proneness predicts coronary heart disease risk: prospective analysis from the atherosclerosis risk in communities (ARIC) study. Circulation 2000;101:2034-9.

15 Everson SA, Kauhanen J, Kaplan GA, et al. Hostility and increased risk of mortality and acute myocardial infarction: the mediating role of behavioral risk factors. Am J Epidemiol 1997; 146:142-52

16 Penninx BW, Guralnik JM, Pahor M, et al. Chronically depressed mood and cancer risk in older persons. J Natl Cancer Inst 1998;90:1888-93.

17 Protheroe D, Turvey K, Horgan K, et al. Stressful life events and difficulties and onset of breast cancer: case-control study. BMJ 1999;319:1027-30.

18 Schapiro IR, Ross-Petersen L, Saelan $\mathrm{H}$, et al. Extroversion and neuroticism and the associated risk of cancer: a Danish cohort study. Am J Epidemiol $2001 ; 153: 757-63$

19 Neeleman J, Wessely S, Wadsworth M. Predictors of suicide, accidental death, and premature natural death in a general population birth cohort. Lancet 1997:351:93-7.

20 Friedman HS, Tucker JS, Tomlinson-Keasey C, et al. Does childhood personality predict longevity? J Pers Soc Psychol 1993;65:176-85.

21 Paffenbarger RS Jr, Notkin J, Krueger DE, et al. Chronic disease in former college students. II.Methods of study and observations on mortality from coronary heart disease. Am J Public Health 1966;56:962-71.

22 Paffenbarger RS, Wing AL. Characteristics in youth predisposing to fatal stroke in later years. Lancet 1967;i:753-4.

23 Paffenbarger R, Wolfwe $\mathrm{P}$, Notkin J, et al. Chronic disease in former college students I. Early precursors of fatal coronary heart disease. Am J Epidemiol 1965;83:314-28.

24 Cole SR, Kawachi I, Sesso HD, et al. Sense of exhaustion and coronary heart disease among college alumni. Am J Cardiol 1999;84:1401-5

25 Graves PL, Mead LA, Wang NY, et al. Temperament as a potential predictor of mortality: evidence from a 41 -year prospective study. J Behav Med 1994; 17:111-26.

26 Siegler IC, Peterson BL, Barefoot JC, et al. Hostility during late adolescence predicts coronary risk factors at mid-life. Am J Epidemiol 1992;136:146-54

27 Simons DB, Schwartz RS, Edwards WD, et al. Noninvasive definition of anatomic coronary artery disease by ultrafast computed tomographic scanning: a quantitative pathologic comparison study. J Am Coll Cardiol 1992;20:1118-26.

28 Iribarren C, Sidney S, Bild DE, et al. Association of hostility with coronary artery calcification in young adults: the CARDIA study. Coronary Artery Risk Development in Young Adults. JAMA 2000;283:2546-51.

29 Meltzer H, Gill B, Petticrew M, et al. The prevalence of psychiatric morbidity among adults living in private households. London: HMSO, 1995.

30 McCarron P, Davey Smith G, Okasha M, et al. Life course exposure and later disease: a follow-up study based on medical examinations carried out in Glasgow University (1948-68). Public Health 1999;1 13:265-71.

31 Stansfeld S, Marmot M. Stress and the heart: psychosocial pathways to coronary heart disease. London: BMJ Publishing, 2002.

32 Office of Population Censuses and Surveys. The General Household Survey 1975. London: HMSO, 1978

33 Anda RF, Williamson DF, Escobedo LG, et al. Depression and the dynamics of smoking. A national perspective. JAMA 1990;264:1541-5.

34 Carney RM, Saunders RD, Freedland KE, et al. Association of depression with reduced heart rate variability in coronary artery disease. Am J Cardiol 1995;76:562-4

35 Tate RB, Manfreda J, Krahn AD, et al. Tracking of blood pressure over a 40year period in the University of Manitoba Follow-up Study, 1948-1988. Am J Epidemiol 1995; 142:946-54.

36 Stoney CM, Bausserman L, Niaura R, et al. Lipid reactivity to stress: II. Biological and behavioral influences. Health Psychol 1999;18:251-61.

37 Stoney CM, Niaura R, Bausserman L, et al. Lipid reactivity to stress: I. Comparison of chronic and acute stress responses in middle-aged airline pilots. Health Psychol 1999; 18:241-50.

38 Biorntorp P. Diabetes. In: Chadwick DJ, ed. The origins and consequences of obesity. Chichester: Wiley, 1996:68-89.

39 Barker DJP. Growth in utero and coronary heart disease. Nutr Rev 1996:54:S1-7.

40 Shanks N, Larocque S, Meaney MJ. Neonatal endotoxin exposure alters the development of the hypothalamic-pituitary-adrenal axis: early illness and later responsivity to stress. J Neurosci 1995; 15:376-84.

41 Nemeroff CB, Musselman DL. Are platelets the link between depression and ischemic heart disease? Am Heart J 2000;140(suppl 4):57-62. 